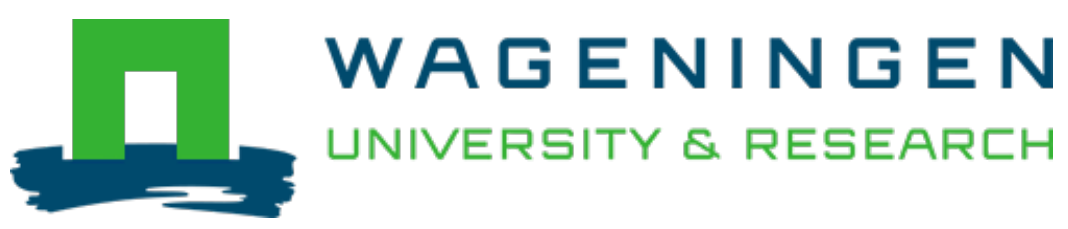

\title{
Accuracy of estimates of milk production per lactation from limited test-day and recall data collected at smallholder dairy farms
}

\section{Livestock Science}

Migose, S.A.; Linden, A.; Bebe, B.O.; Boer, I.J.M.; Oosting, S.J.

https://doi.org/10.1016/j.livsci.2019.103911

This article is made publicly available in the institutional repository of Wageningen University and Research, under the terms of article $25 \mathrm{fa}$ of the Dutch Copyright Act, also known as the Amendment Taverne. This has been done with explicit consent by the author.

Article 25 fa states that the author of a short scientific work funded either wholly or partially by Dutch public funds is entitled to make that work publicly available for no consideration following a reasonable period of time after the work was first published, provided that clear reference is made to the source of the first publication of the work.

This publication is distributed under The Association of Universities in the Netherlands (VSNU) 'Article $25 \mathrm{fa}$ implementation' project. In this project research outputs of researchers employed by Dutch Universities that comply with the legal requirements of Article $25 \mathrm{fa}$ of the Dutch Copyright Act are distributed online and free of cost or other barriers in institutional repositories. Research outputs are distributed six months after their first online publication in the original published version and with proper attribution to the source of the original publication.

You are permitted to download and use the publication for personal purposes. All rights remain with the author(s) and / or copyright owner(s) of this work. Any use of the publication or parts of it other than authorised under article $25 \mathrm{fa}$ of the Dutch Copyright act is prohibited. Wageningen University \& Research and the author(s) of this publication shall not be held responsible or liable for any damages resulting from your (re)use of this publication.

For questions regarding the public availability of this article please contact openscience.library@wur.nl 


\title{
Accuracy of estimates of milk production per lactation from limited test-day and recall data collected at smallholder dairy farms
}

\author{
S.A. Migose ${ }^{\mathrm{a}, \mathrm{b}, \mathrm{c}, *}$, A. van der Linden ${ }^{\mathrm{a}}$, B.O. Bebe ${ }^{\mathrm{b}}$, I.J.M. de Boer ${ }^{\mathrm{a}}$, S.J. Oosting ${ }^{\mathrm{a}}$ \\ ${ }^{a}$ Animal Production Systems group, Wageningen University \& Research, PO Box 338, 6700 AH Wageningen, the Netherlands \\ ${ }^{\mathrm{b}}$ Department of Animal Sciences, Livestock Production Systems group, Egerton University, PO Box 536, 20115 Egerton, Kenya \\ ${ }^{\mathrm{c}}$ Department of Agricultural Resource Management, University of Embu, PO Box 6, 60100 Embu, Kenya
}

\section{A R T I C L E I N F O}

\section{Keywords:}

Accuracy

Cattle

Data scarcity

Developing countries

Tropics

\begin{abstract}
A B S T R A C T
Milk production per lactation (MPL) is a key metric of dairy farms. Accurate estimation of MPL requires regular recording, which is laborious and costly. In smallholder systems in the tropics, therefore, generally very few records are available to estimate MPL. Cross-sectional studies collect only one single record per lactation, and even longitudinal studies usually yield only a limited number of records per lactation. Such data recording methods, therefore, are sometimes extended with records recalled by farmers. The accuracy of MPL-estimates based on such limited and imperfect data, however, is unknown. The aim of the present study was to assess the accuracy of MPL-estimates from a single record and a limited number of records per lactation, obtained from smallholder dairy farms in Nakuru County, Kenya. Test-day records from a milk recording scheme for 114 smallholders were used to prepare three datasets with: i) a complete number of test-days (CTD, 5803 records), ii) a limited number of test-days (LTD, 1583 records), and iii) a single test-day (STD, 471 records). In addition, farmers' recall data (i.e. farmers retrieve information from the past, through memory) from a survey of 29 farms with 56 lactations were used to prepare two datasets with: i) a limited number of recall moments per lactation (LRM, 200 records), and ii) a single recall moment per lactation (SRM, 56 records). These five datasets were used to derive MPL-estimates, at individual cow level or at herd level. The latter was done to mimic a situation without individual cow data, but only herd data (i.e. yield and size). MPL-estimates for CTD were set as a benchmark to quantify the accuracies, based on the relative mean absolute error (RMAE) and root mean square error (RMSE), of MPL-estimates for LTD and STD. As a benchmark dataset was absent for recall data, we computed a virtual benchmark to quantify the accuracies of MPL-estimates for LRM and SRM. At cow level, accuracy of MPL-estimates was highest for LTD (RMAE 15\%), and lowest for SRM (RMAE 28\%), while accuracies for STD and LRM were intermediate (RMAEs 20\%). At herd level, accuracy was higher for STD (RMAE 13\%) than for SRM (RMAE 25\%). We also showed that to detect a difference of, for example, $100 \mathrm{~kg}$ in MPL we need 3002 cows for CTD, and between 3620 and 5003 cows when using alternative data collection methods. Hence, depending on the study objective, alternative data recording methods provide labor-saving and cost-effective ways to estimate MPL in data-scarce smallholder dairy systems.
\end{abstract}

\section{Introduction}

Accurate estimates of milk production per lactation (MPL) are key to evaluate the phenotypic and genetic performance of individual cows in specific parities (Pica-Ciamarra et al., 2014). MPL estimation is important for economic studies or studies for feed and health interventions also. Effects and cost-benefit relations differ among different stages in the lactation curves. Presently, effects are often studied in cross-sectional studies. Estimation of MPL from cross-sectional information (plus recall) corrects for such temporal variation and will increase the quality of on-farm research in tropical farming systems. MPL is generally estimated from several measurements of milk production at specific moments in time $(\mathrm{t})$ during the lactation $\left(\mathrm{MP}_{\mathrm{t}}\right)$. The most accurate estimates of MPL are obtained through regular longitudinal recording of $\mathrm{MP}_{\mathrm{t}}$ throughout the lactation. Such longitudinal records are obtained from automatic milking systems or through repeated recording of milk production throughout the lactation by farmers, researchers or extension officers (ICAR, 2017; Zezza et al., 2016; Ojango et al., 2019). In smallholder systems in developing countries, however, longitudinal records are generally scarce due to

\footnotetext{
* Corresponding author at: Animal Production Systems group, Wageningen University \& Research, PO Box 338, 6700 AH Wageningen, the Netherlands.

E-mail address: migose.salome@embuni.ac.ke (S.A. Migose).
} 
multiple constraints, including infrastructure, skills and level of organization required to collect reliable records, and farmers perceive little value in collecting records (Desiere et al., 2016; Pica-Ciamarra et al., 2014; Rege et al., 2011; Zezza et al., 2016). Data on milk production per lactation for dairy cattle, often, are incomplete and based on farmers' recall (i.e. farmers retrieve information from the past, through memory) instead of on recorded measurement, what can be termed as imperfect data' (Fraval et al., 2018). Besides, other indicators, such as feeding regime and parity, can be used to improve predictions of MPL, but such indicators are often not recorded at smallholder farms. In addition, the feeding regime (i.e. feed availability and feed quality at smallholder farms) is highly variable from season to season, but even from week to week. Estimating MPL based on imperfect data is thus a challenge.

Only a small proportion of farms in developing countries keeps frequent longitudinal records on milk production. In the Kenyan highlands, where resource-limited smallholder farming is dominant, less than one percent of all farms participates in test-day (TD) recording programs (Kosgey et al., 2011; Trivedi, 1997). Full participation of a farmer in a TD recording program implies that $\mathrm{MP}_{\mathrm{t}}$ is measured at least eight times at regular intervals throughout a lactation (ICAR, 2017). These TD data are used in breeding programs to estimate breeding values of MPL (Muasya et al., 2014). The scarcity of frequent longitudinal milk production records has driven the search for alternative data recording methods that estimate MPL based on less records per lactation. This can be through a limited number of TD records per lactation, but it can be done also by using farmer recall data, where farmers rely on memory and recollection to give information for events in the past (Kong et al., 2018; McGill et al., 2014; Zezza et al., 2016). Ideally, farmers participating in recall surveys provide information about $\mathrm{MP}_{\mathrm{t}}$ at several distinctive days in the past from their memory. However, in many surveys, farmers are asked to recall the $\mathrm{MP}_{\mathrm{t}}$ on the day of a farm visit only. Moreover, farmers can be asked to recall milk production of individual cows, but also of the herd in total. The average production of individual cows is then estimated by dividing the whole farm production by the number of adult cows (Zezza et al., 2016).

It is likely that estimates of MPL from alternative data recording methods using imperfect data have a lower accuracy than estimates using data from a full TD program. Few studies have explored the accuracy of estimates of MPL that are based on methods using a limited number of TD-records (Berry et al., 2005; Duclos et al., 2008; Flores et al., 2013; McGill et al., 2014; Van Raden, 1997) or using recall data (Zezza et al., 2016). So far, however, none of these studies compared the accuracy of MPL-estimates based on alternative data recording methods with MPL-estimates based on full data from TD recording programs. Our aim, therefore, was to assess the accuracy of MPL-estimates based on four alternative data recording methods i.e. a limited number of TDs per lactation, a single TD per lactation, a limited number of recall records per lactation, and a single recall record per lactation. Knowledge of the accuracies of these alternative methods is relevant to design cost-effective approaches for, among others, evaluation of breeding programs, the impact of feeding strategies on milk production, or economic performance of resource-limited smallholder farms.

\section{Material and methods}

\subsection{Data collection}

Test-day and recall data were collected to assess the accuracies of MPL using different alternative methods for data recording, namely; collecting i) a limited number of TDs per lactation, ii) a single TD per lactation, iii) a limited number of recall records per lactation, and iv) a single recall record per lactation. Test-day data were obtained from the Livestock Recording Centre, a department of the Ministry of Agriculture, Livestock and Fisheries of Kenya. The Livestock Recording Centre obtains TD data from the national performance recording scheme operated by the Dairy Recording Services of Kenya (DRSK). According to the standard monthly TD recording procedure, farmers submitted their milk production records for individual cows on the 4th evening and the 5th morning after calving, and thereafter on the 14th evening and the 15th morning of the month, until drying-off (ICAR, 2017). The $\mathrm{MP}_{\mathrm{t}}$ for each TD was calculated as the sum of the milk production records for the evening and morning of the TD (ICAR, 2017), as described in detail in Wasike et al. (2011) and Muasya et al. (2014). In addition to milk production records, the DRSK records included unique farm identification number, cow identification number, parity, calving date, and breed. Farmers submitted records for exotic dairy breeds, i.e. breeds that are non-native to tropical countries, and for their crossbreds with native breeds ( $>75 \%$ exotic genotypes). Holstein-Friesian and Ayrshire are the main exotic breeds recorded in the scheme (Kosgey et al., 2011; Njubi et al., 2009). The scheme does not record information about feeding regime. The TD records are submitted by smallholder farms as well as by medium- and large-scale farms $(n=457)$ from all parts of Kenya. We selected 242 farms out of the total of 457 farms in the scheme, based on the criterion that they submitted records for maximally ten cows per year. This resulted in 9872 TD records that represented 988 cows and 1234 lactations. These selected TD data were recorded between November 2002 and April 2015. The majority of smallholder farms that submitted TD records were within Nakuru County, located in the Kenyan highlands (Kosgey et al., 2011).

Smallholder dairy farming in Nakuru County has been described in Migose et al. (2018). In brief, most smallholder dairy farms have less than ten cows, mainly Holstein-Friesian or Ayrshire cattle, or crosses of Holstein-Friesian or Ayrshire cattle with native breeds. Like in the other parts of the highlands, cows are mostly kept in (semi)-intensive or extensive systems and fed on grass pasture and supplemented with Napier grass, maize stover and concentrate (Ojango et al., 2019). Breeding is by artificial insemination or by bulls. Cows calve year-round and can lactate beyond one year. Cows are generally milked by hand and milking is done in the morning and evening. The moment of drying-off varies among farms and cows and can range from 30 to 90 days prior to calving. However, the average drying-off of 2 months ( 60 days) prior to calving is recommended in extension advisory and was thus assumed for this study (ILRI, 2015; Njubi et al., 1992).

Recall data were collected through a cross-sectional survey conducted in Nakuru county. Stakeholders, such as extension agents, inseminators and milk transporters, were asked to refer smallholder farmers whom they interacted with, and the referred farmers also referred new farmers. Farms were visited once between December 2014 and April 2015. Interviews were conducted with each farmer. The identification name of each lactating cow was recorded. For each cow, farmers were asked to recall the date of the last calving, the date of the last service, the pregnancy status, the parity, and the $\mathrm{MP}_{\mathrm{t}}$ for four moments in time, i.e. at the day of the farm visit $\left(\mathrm{MP}_{\mathrm{r}}\right)$, the start $\left(\mathrm{MP}_{\mathrm{s}}\right)$ and peak $\left(\mathrm{MP}_{\mathrm{p}}\right)$ of the lactation, and the day of drying-off $\left(\mathrm{MP}_{\mathrm{d}}\right)$. The $\mathrm{MP}_{s}$ corresponded to $\mathrm{MP}_{t}$ for the first week after calving, and the $\mathrm{MP}_{\mathrm{p}}$ was defined as the highest $\mathrm{MP}_{\mathrm{t}}$ in a lactation, assumed to occur around 55 days in milk (Muasya et al., 2014). For multiparous cows that were not in peak lactation yet, the future $\mathrm{MP}_{\mathrm{p}}$ was assumed to correspond with the recalled $M P_{p}$ in the previous lactation. The $\mathrm{MP}_{\mathrm{d}}$ was recalled from the $\mathrm{MP}_{\mathrm{t}}$ at drying-off in the previous lactation also. For primiparous cows, $\mathrm{MP}_{\mathrm{s}}$ and $\mathrm{MP}_{\mathrm{r}}$ were recalled, and $\mathrm{MP}_{\mathrm{p}}$ was recalled if the cow had reached peak production already. The $\mathrm{MP}_{\mathrm{d}}$ is not available for lactating primiparous cows yet. Only for $\mathrm{MP}_{\mathrm{r}}$, the evening and morning milk was recalled separately and summed to calculate $\mathrm{MP}_{\mathrm{t}}$ for the day, for the other three moments, an average daily milk production was recalled. None of the farms surveyed was participating in the TD recording scheme. In the survey no data were collected about the feeding regime. Data were collected under permit from the National Commission for Science, Technology, and Innovation, Kenya. 


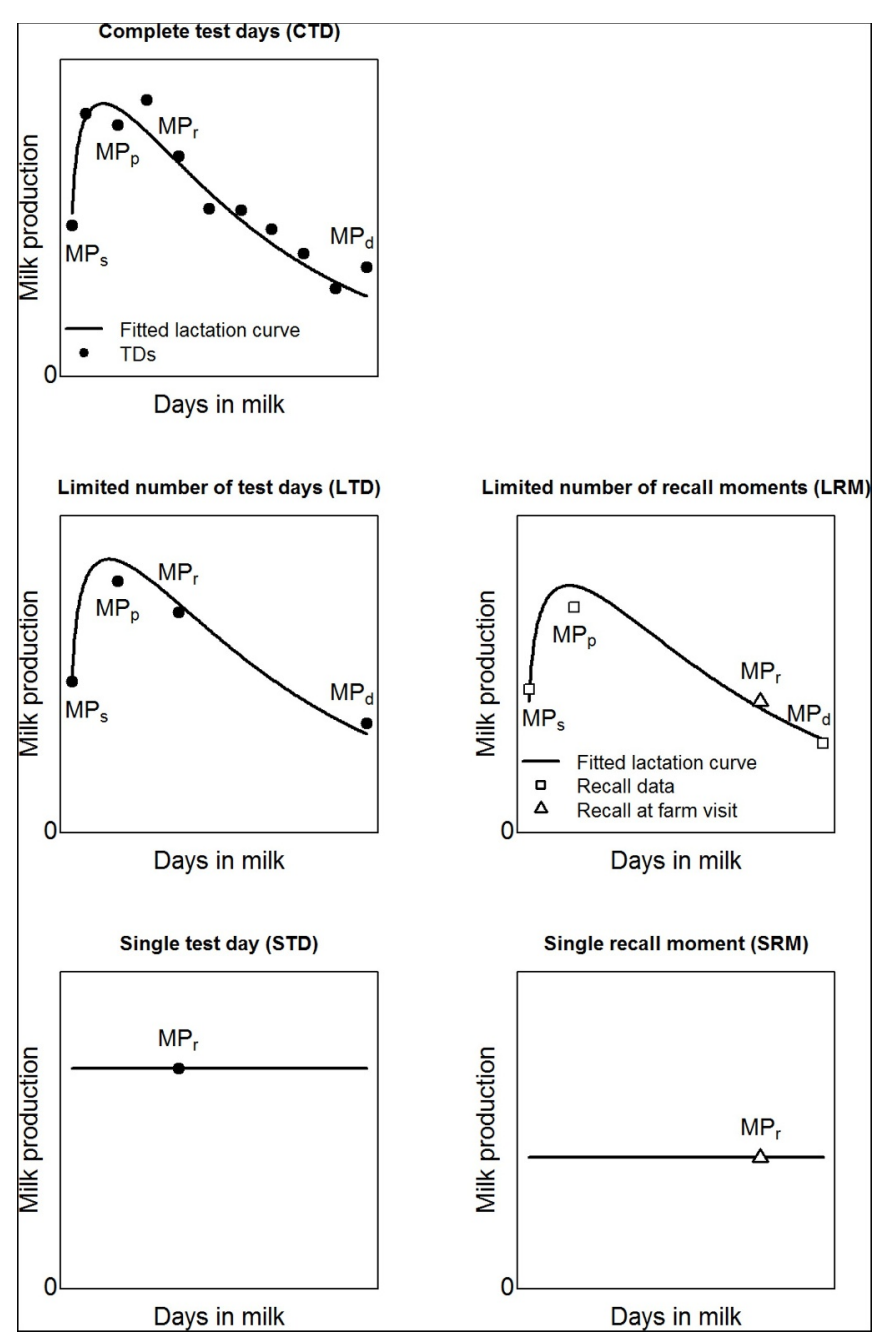

Fig. 1. An overview of the five datasets created to estimate the accuracy of milk production per lactation. $\mathrm{MP}_{\mathrm{s}}=$ milk production at the start of the lactation (5-8 days in milk), $\mathrm{MP}_{\mathrm{p}}=$ milk production at peak lactation (55 days in milk), $\mathrm{MP}_{\mathrm{r}}=$ milk production at a random day in the lactation, corresponds to farm visit, $\mathrm{MP}_{\mathrm{d}}=$ milk production at drying-off, $\mathrm{TD}=$ test-day.

\subsection{Preparation of datasets}

We prepared three datasets from the data collected through TD recording: the first had records for a complete number of TDs (CTD), including at least eight TDs per lactation; the second had records for a limited number of TDs (LTD), including three or four TDs per lactation; and the third had records for a single TD (STD) per lactation. We prepared two datasets from the recall data collected through the survey: the first had records for a limited number of recall moments (LRM), i.e. three or four moments per lactation, and the second had records for a single recall moment (SRM), i.e. one moment per lactation. Recall data included a maximum of four milk production moments per lactation, and therefore a dataset with a complete number of recall moments, equivalent to CTD, was unavailable for this study (Fig. 1).

\subsubsection{Complete test-day dataset}

Lactations were excluded from the TD data based on the following criteria: if less than eight TDs were available per lactation, if records were missing for three consecutive TDs before the eighth TD, if the $\mathrm{MP}_{\mathrm{t}}$ at two consecutive TDs differed by more than 50\% (ICAR, 2017), and if the first TD was submitted earlier than five days after calving. Farmers did not always submit TD records for the specified monthly recording date, i.e. the evening of the 14 th and the morning of the 15th. As a
Table 1

The number of farms, cows, lactations, and milk production records in the datasets for test-day (TD) and recall data.

\begin{tabular}{llllll}
\hline Data source & Dataset $^{\mathrm{a}}$ & Farms & Cows & Lactations & Records \\
\hline \multirow{2}{*}{ Test-day } & Complete TDs & 114 & 386 & 532 & 5803 \\
& Limited number of TDs & 112 & 354 & 471 & 1583 \\
\multirow{3}{*}{ Recall } & Single TD & 112 & 354 & 471 & 471 \\
& Limited number of recall & 29 & 56 & 56 & 200 \\
& moments & 29 & 56 & 56 & 56 \\
\hline
\end{tabular}

${ }^{\text {a }}$ Datasets consisting of a limited number of TDs and a single TD per lactation were constructed ten times to avoid bias due to selection of a random TD. Values indicate the averages for the ten datasets.

result, some TDs were not available for the specified recording date or were recorded more than once per month. In such occasions, the TD closest to the specified monthly recording date was adopted. The last TD recorded in a lactation was assumed to be the TD at drying-off. In total, the CTD dataset contained 5803 records from 532 lactations (average: 10.9 records per lactation) of 386 cows that were kept on 114 farms (Table 1).

\subsubsection{Limited number of test-day and single test-day datasets}

The LTD dataset was constructed from the CTD dataset and included three or four TDs per lactation, which mimicked the four moments of collecting milk records in the recall survey, i.e. $\mathrm{MP}_{\mathrm{s}}, \mathrm{MP}_{\mathrm{p}}, \mathrm{MP}_{\mathrm{r}}$ and $\mathrm{MP}_{\mathrm{d}}$. These four TDs were selected as follows: the first TD (5-8 days) corresponds to $\mathrm{MP}_{\mathrm{s}}$ and the last TD corresponds to $\mathrm{MP}_{\mathrm{d}}$, the third TD (39-68 days in milk, average 55 days in milk) corresponds to the $\mathrm{MP}_{\mathrm{p}}$, and finally, one TD was randomly selected from all available TDs to mimic MP $\mathrm{P}_{\mathrm{r}}$ (Fig. 1). Because $\mathrm{MP}_{\mathrm{r}}$ was collected on the day of the farm visit and farm visits occurred at random moments during a lactation, the TD that corresponds with $\mathrm{MP}_{\mathrm{r}}$ was selected randomly. To this end, we used the 'sample' function in R ( $\mathrm{R}$ core Team, 2018). If the randomly chosen $\mathrm{MP}_{\mathrm{r}}$ corresponded to either $\mathrm{MP}_{\mathrm{s}}, \mathrm{MP}_{\mathrm{p}}$ or $\mathrm{MP}_{\mathrm{d}}$, the TD was only included once, which resulted in three records per lactation. Only lactations with three or four records per lactation were included in the LTD dataset. The $\mathrm{MP}_{\mathrm{d}}$ was available for all lactations due to the assumption that drying-off corresponded to the last TD. Seven lactations were excluded because both $\mathrm{MP}_{\mathrm{s}}$ and $\mathrm{MP}_{\mathrm{p}}$ were missing, resulting in two records per lactation only. On several occasions, either $\mathrm{MP}_{\mathrm{s}}$ or $\mathrm{MP}_{\mathrm{p}}$ was missing and $\mathrm{MP}_{\mathrm{r}}$ corresponded to one of the two available records, which resulted in having only two records per lactation $\left(\mathrm{MP}_{\mathrm{d}}\right.$ and either $\mathrm{MP}_{\mathrm{s}}$ or $\left.\mathrm{MP}_{\mathrm{p}}\right)$. These lactations $(n=54)$ were excluded from the LTD datasets as well. The estimates for MPL from the LTD dataset were assumed to be affected by the randomly selected TDs. Therefore, the LTD dataset was created ten times with different random TDs and the ten LTD datasets contained, on average, 1583 records from 471 lactations and 354 cows that were kept at 112 farms (Table 1). In addition, the STD was created from the LTD by selecting the random TD that corresponds to $\mathrm{MP}_{\mathrm{r}}$ (Fig. 1). Because the LTD was created ten times, the STD was selected ten times as well.

\subsubsection{Limited number of recall moments and single recall moment datasets}

The recall data comprised of $\mathrm{MP}_{\mathrm{t}}$ records for maximally four moments per lactation, i.e. $\mathrm{MP}_{\mathrm{s}}, \mathrm{MP}_{\mathrm{p}}, \mathrm{MP}_{\mathrm{r}}$ and $\mathrm{MP}_{\mathrm{d}}$ (Fig. 1). Cows included in the LRM dataset had records for at least three moments out of the four moments, whereas cows with records for two or less moments were excluded. The time at drying-off was calculated as the expected date of the next calving minus 60 days (average dry period (Njubi et al., 1992)). The expected date of the next calving was calculated as the date a cow was served plus the average gestation period, i.e. 285 days. In addition, cows without an expected date of calving were excluded, because this date is essential to calculate MPL. The LRM dataset comprised of 200 records from 56 lactations of 56 cows that were kept in 29 
farms (average: 1.9 cows per farm) (Table 1). Finally, the SRM dataset comprised of 56 records that corresponded to $\mathrm{MP}_{\mathrm{r}}$ in the LRM (Fig. 1).

The five datasets were used to estimate MPL at cow level, where individual lactations are the unit of measurement, and at herd level, where the farm is the unit of measurement (Table 1). This was done because often only the total $\mathrm{MP}_{\mathrm{t}}$ per herd is recalled in cross-sectional surveys. From this farm- $\mathrm{MP}_{\mathrm{t}}$, the average $\mathrm{MP}_{\mathrm{t}}$ per cow is calculated and these average $\mathrm{MP}_{t} s$ are multiplied by the average length of the lactation or the average length of the calving interval (dependent on whether dry cows are excluded or included in the estimation of the average $\mathrm{MP}_{\mathrm{t}}$ ) to calculate MPL (Migose et al., 2018; Zezza et al., 2016).

\subsection{Accuracy of MPL-estimates from limited records per lactation}

\subsubsection{MPL-estimates}

We estimated MPL by fitting lactation curves to the data in CTD, LTD and LRM. Lactation curves can be either typical, i.e. show an initial increase in milk production after calving, up to peak production, and subsequently, a gradual decline up to drying-off, or atypical, i.e. lactation curves with an intercept and a slope, which is either decreasing, constant, or increasing Macciotta et al., 2011 MPL for typical lactation curves is best described by non-linear equations, whereas atypical curves are best described by either a linear equation. To describe the lactation curves, therefore, we used both a non-linear and a linear equation.

The non-linear equation is based on the commonly used Wood's equation. We, however, used the modified Wood's equation, as specified by Jenkins and Ferrell (1984), which requires only two instead of three parameters (Eq. (1)). This equation is better suited, therefore, to estimate MPL if only a limited number (at least three data points) of sparsely distributed lactation data is available (Landete-Castillejos and Gallego, 2000; Sawyer et al., 1994). The equation was developed for crossbred beef cattle in the tropics (Adediran et al., 2007; Jenkins and Ferrell, 1984).

$Y(t)=t \times\left(a \times e^{k t}\right)^{-1}$

where $Y(t)$ is daily milk production on the th week after calving $(\mathrm{kg} /$ day), $t$ is the number of weeks after calving, and $a$ and $k$ are scaling parameters that determine the curvature of the lactation curve.

The linear equation contains one parameter for the slope and one for the intercept. The slope was considered to be decreasing if it was significantly lower than zero, increasing if it was significantly higher than zero, and constant if it was not significantly different from zero. Significant deviations of the slope from zero were determined with a $t$ test.

Other methods, such as random regression and best predictions, can be used to compute MPL and accuracies of MPL estimates from TDs if number of records are limited (Van Raden, 1997). These methods may reduce bias of MPL estimates if only a limited number of TDs are available in early lactation compared to JF or linear equation. However, these methods require training datasets from complete test-day records that allows to establish correlations. Besides, we desired a simple method that works for smallholder farmers.

The JF-equation and linear equation were fitted to the data in CTD, LTD and LRM datasets. Parameters of both equations were fitted in such a way that the difference between the actual and the estimated milk production represented by the root mean squared error (RMSE), was minimized (Bennett et al., 2013). For the LTD, the equations were fitted to all ten datasets and the RMSE was averaged. The equation (either the linear or JF) that resulted in the lowest RMSE was considered to fit best. MPL is integral of the fitted lactation curves from calving up to dryingoff for the CTD, LTD and LRM. MPL for STD and SRM was calculated by multiplying $\mathrm{MP}_{\mathrm{r}}$ and the lactation length.

For curves that were best fitted by a linear equation, we also determined the suitability of the JF-equation to estimate their MPL by quantifying the difference between MPL-estimates by both equations.
This difference was expressed as the mean absolute error (MAE), relative MAE (RMAE), mean squared error (MSE) and RMSE (Bennett et al., 2013). The MSE was decomposed into the bias, slope, and random component using the method of Theil and Rey (1966) and Bibby and Toutenburg (1977). The bias component of the MSE indicates the overall bias in MPL between two equations, the slope component indicates differences in variability in MPL between two equations, and the random component indicates the random variation (Bellocchi et al., 2011).

We derived MPL-estimates at herd level, by averaging MPL-estimates of all individual lactations recorded per farm. The average MPLestimate per cow was calculated for each farm and for each of the five datasets, as described in the previous paragraphs. The sum of $\mathrm{MP}_{\mathrm{r}}$ data for all lactating cows in a herd (i.e. STD and SRM) was assumed to correspond to farmers' estimates of the daily milk production of a farm in the cross-sectional survey (Table 1).

\subsubsection{Accuracy of MPL-estimates from alternative data recording methods}

MPL-estimates from CTD were assumed to closely resemble the actual MPL at farms. CTD was used, therefore, as the benchmark for the MPL-estimates based on LTD and STD. Differences in MPL-estimates between this benchmark and the alternative data recording methods LTD and STD were derived at cow and at herd level. The MPL-estimates were calculated for the 10 sets of LTD and STD and then averaged. Since the benchmark was assumed to resemble the actual MPL, differences from the benchmark were considered to be errors, which were expressed as the MAE, relative MAE, MSE, and RMSE (Bennett et al., 2013). The MSE was decomposed to its bias, slope, and random components, as described before. The larger these errors, the lower the accuracy of the MPL-estimates.

A benchmark dataset equivalent to CTD was absent for recall data Fig. 1), which does not allow to calculate errors between MPL-estimates from LRM or SRM and a benchmark, as was done for TD data. We assumed, therefore, that the proportions in errors of limited and single records relative to a benchmark of complete records were the same for TD and recall data. We assumed, also, that recall bias did not affect the proportions in the errors. Given these assumptions, we calculated the errors for the LRM and SRM using a two-step approach. First, SRM was benchmarked to LRM, and STD was benchmarked to LTD. The error between LRM and SRM was divided by the error between LTD and STD, which resulted in a dimensionless ratio (Eq. (2)). For example, the RMAE between LRM and SRM for individual lactations was $30.7 \%$, and the RMAE between LTD and STD was on average $22.6 \%$ for the 10 datasets, which resulted in a ratio of 1.36 . Second, this ratio was multiplied by the error for LTD to get the error for LRM, and by the error for STD to get the error for SRM (Eqs (3) and (4)). This implies, for example, that the RMAE for the LRM is 1.36 times the RMAE between the benchmark CTD and the alternative data collection method LTD.

Ratio $=$ Error $_{L R M-S R M} /$ Error $_{L T D-S T D}$

Error $_{L R M}=$ Ratio $\times$ Error $_{C T D-L T D}$

Error $_{S R M}=$ Ratio $\times$ Error $_{C T D-S T D}$

Where the Error is expressed as the MAE, RMAE, MSE, and RMSE. The procedure to calculate the error for LRM and SRM was conducted for individual animals and for herds. For herds, the errors were linked to the number of lactations per herd. Using the STD dataset, herds were grouped according to number of lactations, i.e. all herds with one lactation were put in a group. The average RMAE was calculated for each group as the sum of RMAEs per group divided by the number of lactations per group.

\subsection{Effective sample sizes}

The accuracy of MPL-estimates determines the effective sample size of cows or farms with milk production records required to detect 
significant effects of interventions on MPL. Less accurate methods require larger effective sample sizes to detect significant effects (Kanyongo et al., 2007; Mason et al., 2018; Phillips and Jiang, 2016). We determined effective population sizes for each method of data recording. The reliability coefficient, which is similar to the coefficient of determination $\left(R^{2}\right)$ of the regression between the benchmark and each alternative method, was quantified and the resulting $R^{2}$ value was incorporated in the formula described in Cohen (1988) to calculate the effective sample sizes (Eq. (5)).

$\eta=\frac{2 \delta^{2}}{(d)^{2}}$

where $n$ is the effective sample size, $\delta$ is the critical value of $t$ at $t_{1-\alpha}$ and $t_{1-\beta}$, and $d$ is the standardized effect size. The formula is described in detail in the appendix A. We calculated the sample sizes required to detect significant differences ranging from 1 to $1500 \mathrm{~kg}$ of milk per lactation. All analyses in the present study were performed in R (R Core Team, 2018).

\section{Results}

\subsection{Lactation curves}

Majority of lactations derived from CTD and LTD datasets were best described by a linear equation and thus showed an atypical curve, whereas the majority of lactations derived from LRM were best described by a non-linear equation and thus showed typical curve (Table 2).

The atypical curves derived from CTD were mostly decreasing, whereas atypical curves from LTD were mostly constant (Fig. 2).

A generic equation is preferred, however, to estimate MPL in a universal way that can be recommended to others for the collection of milk production data on farms. It was tested, therefore, whether the JFequation was also suitable as a generic equation for atypical lactations best described by the linear equation, by exploring the differences in MPL-estimates between the fitted JF-equation and the fitted linear equation. The RMAE was $4 \%$ of MPL for CTD (Table 3) and estimates derived from both equations were quite similar (Fig. 3). The average RMAE was $13 \%$ of MPL for the LTD, and $14 \%$ of MPL for the LRM (Table 3). Linear and non-linear estimates of MPL based on LRM differed from each other as shown by the deviation from the $x=y$ line in Fig. 3. Thus, the JF-equation estimated MPL for atypical curves in CTD with a small RMAE and, also, for LTD, since LTD was part of CTD. Though the JF-equation applied to the atypical curves in LRM resulted in an error for some animals, the majority of curves in LRM were best described by a JF-equation (Table 2). Hence, we conclude that it is justified to use the JF-equation to estimate MPL for both TD and recall data.

\subsection{Accuracy of MPL-estimates from limited records per lactation}

The RMAE for STD derived at herd level was 13\%, and the RMAE for LTD derived at cow level was $15 \%$. These two RMAEs were the lowest
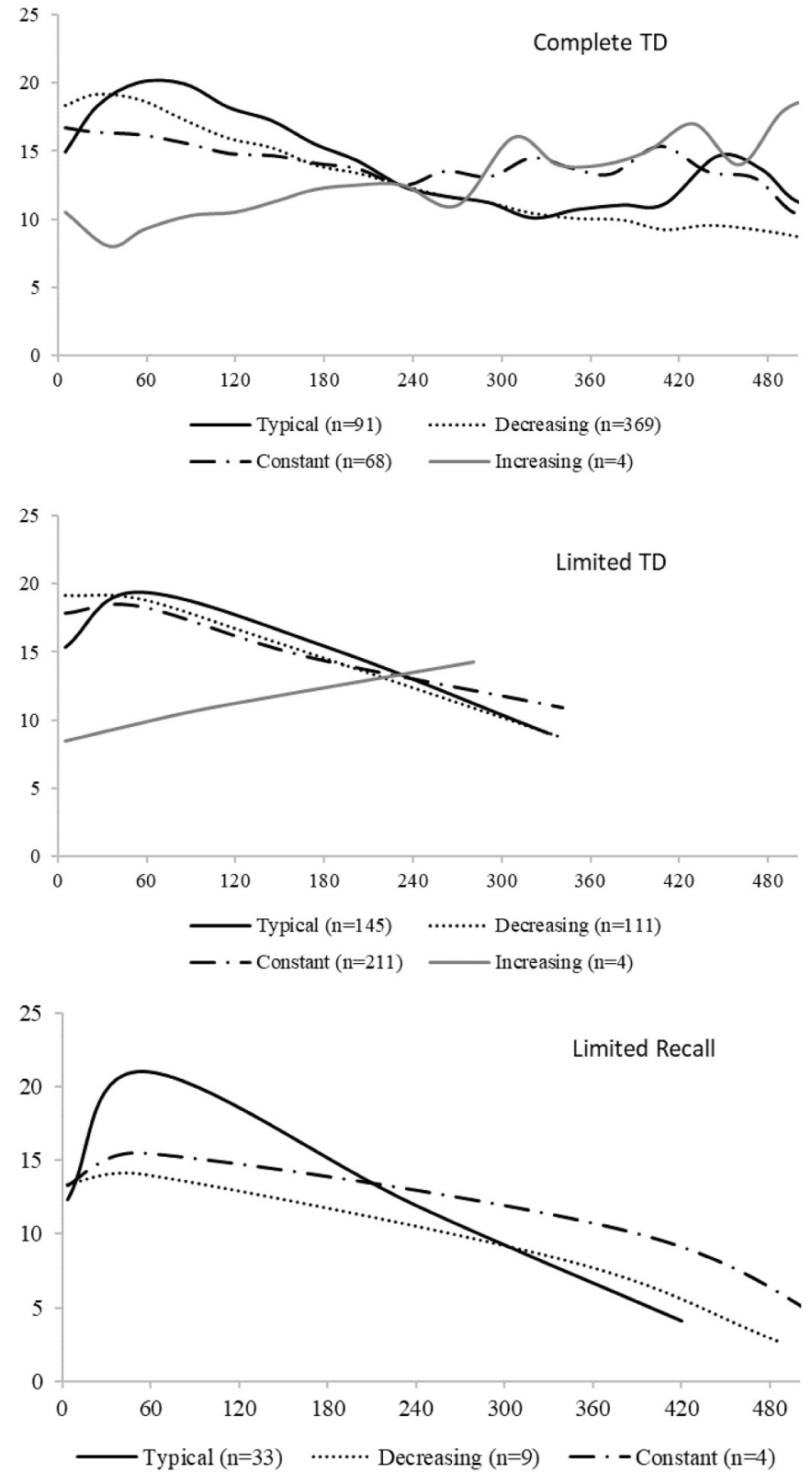

Fig. 2. Typical, decreasing, constant and increasing lactation curves for incomplete test-day complete test-day and recall datasets.

among the RMAEs for all alternative methods (Table 4), and consequently, these two methods for estimating MPL were most accurate. The RMAEs for STD (20\%) and LRM (20\%) derived at cow level and for SRM derived at herd level (21\%) were intermediate. The RMAE for SRM derived at cow level was the highest (Table 4), which implies that using

Table 2

Percentages of lactations best fitted by a Jenkins and Ferrell (JF) equation (typical) or a linear equation (atypical) in the complete test-days (TDs) dataset, limited number of TDs dataset and limited number of recall moments dataset.

\begin{tabular}{lllll}
\hline Lactation curve & Slope & Complete TDs $(n=532)$ & Limited number of TDs $(n=471)^{\mathrm{a}}$ & Limited number of recall moments $(n=56)$ \\
\hline Best fitted by JF equation (typical, \%) & - & 17.1 & $28.8 \pm 0.5$ & 66.1 \\
Best fitted by a linear equation (atypical, \%) & Decreasing & 69.4 & $24.0 \pm 0.4$ & 14.3 \\
& Constant, \% & 12.8 & $46.7 \pm 0.6$ & 19.6 \\
& Increasing, \% & 0.8 & $0.5 \pm 0.1$ & 0.0 \\
\hline
\end{tabular}

a The limited number of TDs dataset was derived from the complete TDs dataset, using the milk production at the start, peak, drying-off, and a random TD in the lactation. The random TD for each lactation was selected ten times and consequently lactation curves were fitted ten times. Values represent average percentages and standard errors of ten repeated analyses. 
Table 3

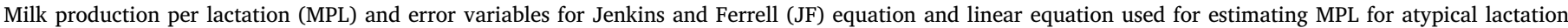
curves in the complete test-day (TD) dataset, limited number of TDs dataset, and limited number of recall moments dataset.

\begin{tabular}{|c|c|c|c|}
\hline Variable & Complete TDs $(n=441)$ & Limited number of TDs $(n=336)^{\mathrm{a}}$ & Limited number of recall moments $(n=19)$ \\
\hline MPL - Linear, kg & 4939 & 4995 & 3943 \\
\hline MPL - JF, kg & 4764 & 5143 & 2744 \\
\hline Mean absolute error, $\mathrm{kg}$ & 184 & 636 & 1273 \\
\hline Relative mean absolute error, $\%$ & 3.7 & 12.7 & 13.8 \\
\hline Root mean square error, $\mathrm{kg}$ & 244 & 1010 & 1922 \\
\hline Bias, $\%$ of $\mathrm{MSE}^{\mathrm{b}}$ & 51.4 & 2.3 & 38.9 \\
\hline Slope, $\%$ of MSE ${ }^{\mathrm{b}}$ & 5.7 & 36.3 & 13.8 \\
\hline Random, $\%$ of MSE ${ }^{\mathrm{b}}$ & 42.9 & 61.5 & 54.1 \\
\hline
\end{tabular}

a Limited number of TDs dataset was derived from the complete TDs dataset, using the milk production at the start, peak, drying-off, and a random TD in the

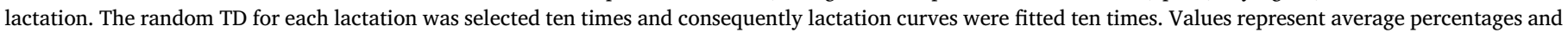
standard errors of ten repeated analyses.

${ }^{\mathrm{b}}$ Bias = MSE decomposed into error due to the overall bias of prediction; Slope = MSE decomposed into error due to the deviation of the regression slope from unity; Random = MSE decomposed into error due to the random variation.
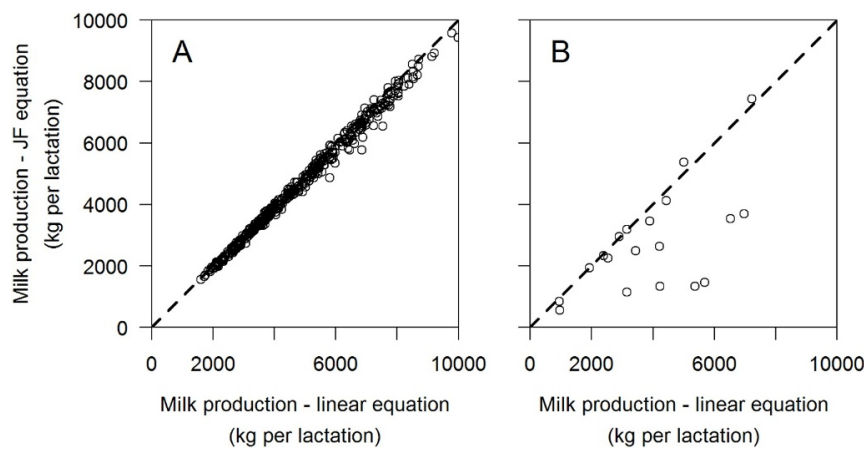

Fig. 3. Relation between milk production per lactation estimated by the Jenkins and Ferrell (JF) equation and by a linear equation for the complete testday (CTD) dataset (A) and the limited number of recall moments (LRM) dataset (B). The dashed line is the $x=y$ line.

this method to estimate MPL is the least accurate of the alternative methods assessed. The random component of MSE for STD derived at herd level was 77\%, and the bias and slope components of MSE were $23 \%$ together, which suggest that most of the RMSE was related to random variation (Table 4). Random variation is expected to decrease at herd level if more lactations are recorded per herd, and RMAEs are expected to decrease with an increasing number of lactations recorded per herd. The RMAEs for STD decreased indeed with increasing number of lactations per herd (Fig. 4).

Herds with one or two lactations had RMAEs that were higher than the average RMAE for all herds (13\%). The RMAE was approximately half or even less for herds that submitted records for 13 or more lactations (Fig. 4).

\subsection{Effective sample sizes}

We calculated the effective sample size, for the benchmark, given a coefficient of determination $\left(R^{2}\right)$ of 1.0, and for the alternative methods of estimating MPL, using the following $R^{2}$ s: 0.83 for LTD, 0.72 for LRM, 0.69 for STD and 0.60 for SRM at cow level, and 0.83 for STD and 0.62 for SRM at herd level. The effective sample sizes decreased with increasing differences in MPL to be discriminated and with increasing value of coefficient of determination (Fig. 5). To detect small differences in MPL, i.e. $<100 \mathrm{~kg}$, we need an effective sample size of more than 3000 cows and 2400 farms (Fig. 5). For example, a detectable difference in MPL of $100 \mathrm{~kg}$ required 3002 cows for CTD, and between 3620 and 5003 cows for alternative methods, whereas a detectable difference of $600 \mathrm{~kg}$ required 85 cows for CTD and between 102 and 141 cows for alternative methods. The effective sample sizes were slightly smaller for farms than for cows: at a similar detectable difference, the effective sample size using CTD at the farm level was $80-81 \%$ of the effective sample size using CTD at the cow level.

Table 4

Mean milk production per lactation and estimation errors for various datasets from test-day (TD) and recall data at cow and herd level.

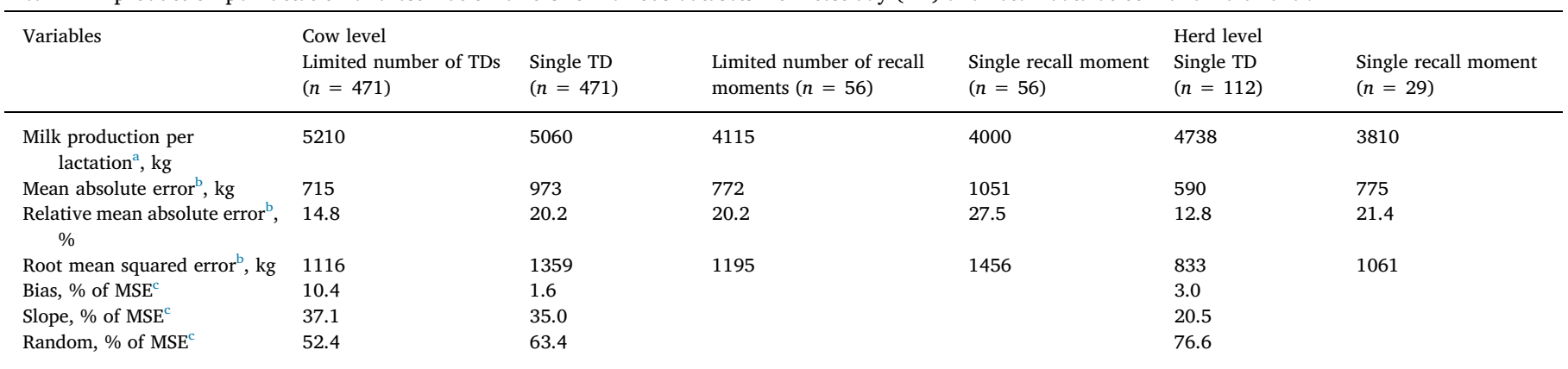

${ }^{a}$ Milk production per lactation (standard deviation) for complete test-days (TDs) dataset (benchmark for limited number of TDs dataset and single TD dataset) was 4814 (1955) $\mathrm{kg}$ per lactation at cow level $(n=471)$ and 4637 (1748) $\mathrm{kg}$ per lactation at herd level $(n=112)$. The virtual benchmark value for limited number of recall moment, and single recall moment at cow level was $3821 \mathrm{~kg}$ and for single recall moment at herd level was $3621 \mathrm{~kg}$ (only one virtual benchmark per recall dataset).

${ }^{\mathrm{b}}$ Errors are expressed relative to the milk production per lactation from the benchmark datasets.

c The components of the mean squared error (MSE) were not calculated for recall datasets due to the missing benchmark for recall data. 


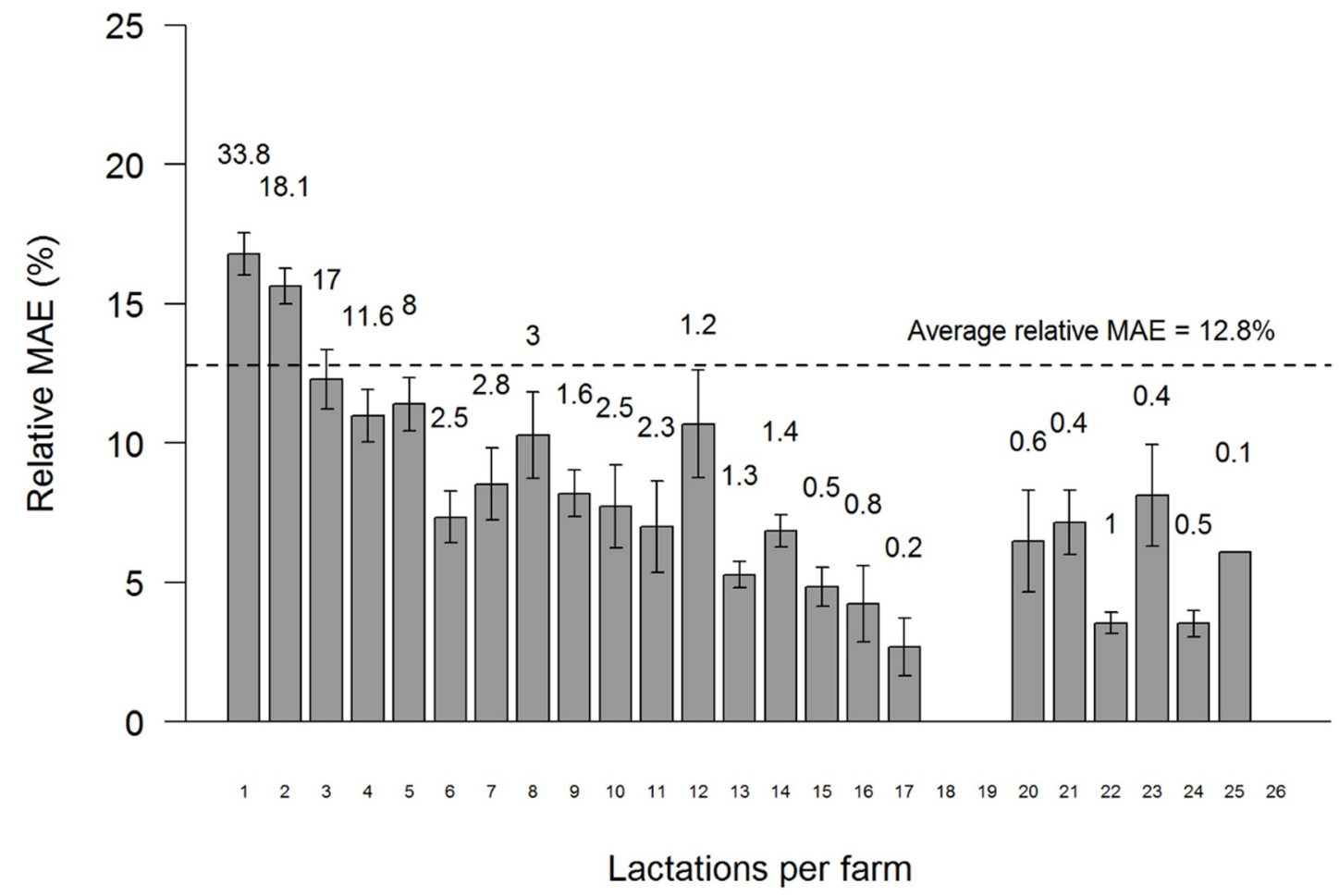

Fig. 4. Relative mean absolute error (MAE) for single test-day records relative to complete test-day records in smallholder dairy farms with 1 up to 25 lactations. Numbers above bars indicate the average number of farms in each class (averaged across 10 repeated analyses).
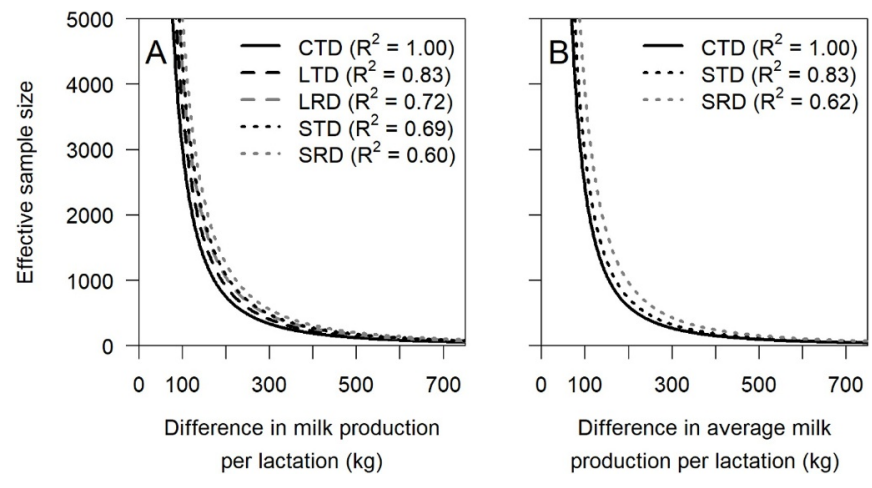

Fig. 5. The relation between effective sample sizes of cows (A) and farms (B) and detectable differences in milk production per lactation.

\section{Discussion}

\subsection{Complete records of the lactation}

The most accurate measure of MPL is obtained from the aggregation of daily milk production records, which are often not available in smallholder systems. Taking records at regular intervals in a lactation, referred to in the present study as CTD with a minimum of 8 records per lactation, has a high correlation with true MPL (Flores et al., 2013; Norman et al., 2009; Quist et al., 2007). Estimation of MPL through such CTD is mostly done in systems with limited day-to-day and limited seasonal variation, i.e. large-scale farms with exotic breeds, and good management. A study that explored the correlation between MPL estimated from CTD and other datasets with limited number of TDs was based predominantly on large-scale farms (Wasike et al., 2011). It is unknown, however, what the accuracy is between true MPL and MPL estimated from CTD on smallholder farms in the tropics. For the present study, we assumed that CTD allows to estimate MPL accurately enough to serve as a benchmark for the alternative methods of MPL estimation.
Most CTD-lactations had atypical, decreasing lactation curves (Table 2). Previous studies about lactations of cows in smallholder farms in Kenya have reported atypical curves, too, and attributed a mild peak or even no peak to a negative energy balance (Katiku et al., 2011; Muraguri et al., 2004; Omore et al., 1996; Staal and Omore, 1998). The JF equation estimated MPL adequately for both typical and atypical curves (Fig. 3).

\subsection{Limited records per lactation}

Accuracy of MPL-estimates based on limited records were expected to be lower than those based on CTD, because the accuracy of MPLestimates decreases with a decrease in number of records per lactation (Berry et al., 2005; Duclos et al., 2008; Flores et al., 2013; Kong et al., 2018; McGill et al., 2014; Otwinowska-Mindur et al., 2014; Zezza et al., 2016, 2016). The accuracy of the LTD method was higher than that of the LRM method (Table 4). For LRM, part of the lower accuracy compared to LTD can be attributed to the so-called recall bias (Godlonton et al., 2018; Zezza et al., 2016). Recall bias is a systematic error caused by differences in the completeness of recollections retrieved by farmers on past events or experiences (Godlonton et al., 2018; Zezza et al., 2016). The magnitude of recall bias is variable and over-reporting of estimates of $30 \%$ has been demonstrated when recall is used instead of ledger books (De Mel et al., 2009). Recall bias may be associated with several factors, including memory failures, farmers' high expectations, illiteracy and conditions at the time of the interview (e.g. duration) (Beegle et al., 2012; de Nicola and Giné, 2014; Deininger et al., 2012). To estimate MPL from LRM, we had to make assumptions about gestation length, length of the dry period, and the moment of peak production. Moreover, in contrast to TD data, which are often obtained through actual weighing or volume recording, recall estimates are subjective. While the accuracy is higher for LTD compared to LRM, we realize that collection of LTD data requires more efforts: multiple farm visits to record the daily milk production of individual lactating cows at different moments during a lactation or organizing farmers to submit three or four TD records for each lactating cow. For 
LRM, on the other hand, only a single farm visit is required.

\subsection{Single record per lactation}

Accuracies of MPL-estimates based on single records were lower than those based on a limited number of TDs (Table 4), which is in line with literature (Liu et al., 2000; Macciotta et al., 2002; OtwinowskaMindur et al., 2014). When only a single record of the lactation is used to estimate MPL, it is assumed that the random daily milk production is representative for the average daily milk production throughout the lactation, implying that variation in daily milk production throughout the lactation is not accounted for. In our study, errors were higher for SRM than for STD and this could potentially be attributed to recall bias, which may be caused by the several factors, already mentioned in the previous paragraph (Beegle et al., 2012; de Nicola and Giné, 2014; Deininger et al., 2012). However, it is likely that recall bias was limited since farmers only had to recall the production for the last $24 \mathrm{~h}$. Nevertheless, wishful thinking associated with the subjective estimation of the milk quantity could be a source of error. Data of a single record per lactation require minimal efforts to collect, but they estimated MPL with a relatively low accuracy, except at herd level, which will be discussed in the next section.

Errors for LRM and SRM datasets, relative to the virtual benchmark, were quantified using a ratio, i.e. errors of SRM when benchmarked to LRM divided by errors of STD when benchmarked to LTD, that relates recall data to TD data. This is a rough assumption and has limitations; it assumes no differences in relative errors between TD and recall data and no effect of recall bias on errors. Ideally, the datasets should contain the same farms, the same cows, and the same lactations for the TD records and recall data, but such data were not available for Nakuru country. In this study, recall data were not related to TD data because farms in the survey were not participating in the TD- scheme. As a result, MPL-estimates based on the LRM and SRM datasets, therefore, could not be benchmarked directly to CTD.

\subsection{Single records of the herd}

If all lactation stages are represented uniformly at a farm, at any random day, the total milk production per farm divided by the number of adult (lactating and dry) cows represents the average daily milk production of a cow during calving interval (Pica-Ciamarra et al., 2014; Zezza et al., 2016). Hence, multiplication of this daily milk production times the average length of the calving interval gives MPL. The more adult cows on a farm, the more accurate the estimation of this average daily milk production (Zezza et al., 2016). This theoretical hypothesis is confirmed by our results (Fig. 4) and in line with PicaCiamarra et al. (2014) and Zezza et al. (2016). The SRM had a lower number of lactations per farm (1-4) than STD (1-25), which explains part of the lower accuracy for SRM than for STD at herd level. The recall bias has likely contributed too (Zezza et al., 2016). Recall data were available only for lactating animals and calculations were based on lactating animals only. Milk production per lactation at herd level was calculated as milk production per day multiplied by the average lactation length. In actual farms, dry cows are part of the herd and MPL per herd is calculated by multiplying the average daily milk production by the average calving interval (Pica-Ciamarra et al., 2014; Zezza et al., 2016). Hence, MPL can be calculated from the lactation length when lactating cows are considered, or from the calving interval when both lactating and dry cows are considered. Estimating MPL using SRM at herd level, however, neglects variation among cows and the estimates cannot be used for interventions that target individual cows.

\subsection{Effective sample sizes}

The increase in effective sample sizes with decreasing detectable differences in MPL-estimates (Fig. 5) has the following implications: a large sample size is required to detect small differences in MPL-estimates, whereas a relatively small sample size is required to detect large differences in MPL. A breeding intervention, such as sire evaluation in Kenya, for example, which in the case of Muasya et al. (2014) has a detectable difference of about $100 \mathrm{~kg}$ milk per lactation, would require approximately 3000 cows for CTD and up to 5000 cows for alternative methods. An intervention, such as concentrate feeding in Kenya, however, is likely to increase daily milk production by approximately $2 \mathrm{~kg}$ per day, equivalent to $600 \mathrm{~kg}$ per lactation (e.g. Mwendia et al., 2018; Richards et al., 2016). Detecting such an effect size would require 85 cows for CTD and between 102 and 141 cows for the alternative methods. The practical implication of the present study is that, to quantify relatively large effect sizes, relatively simple methods of data collection can be done: a single farm visit can be used to collect individual cow records directly or via recall, and even a method where the whole farm production is recorded and divided by the total number of adult cows at a farm gives a reasonable estimates for MPL. Using alternative methods for estimating MPL, such as random regression models proposed by van Raden (1997), may results in different relative MAEs. This implies that, fewer samples than reported in this study (Fig. 5), will be required to detect significant differences when such methods are used to estimate MPL instead of the modified Woods model.

\subsection{Limitations of estimating MPL using recall data}

In the present study, for recall data, we included records for the ongoing lactations only, and without knowing the drying-off date, we estimated the lactation length by assuming a fixed length of the gestation period and a fixed length of the dry period. Hence, a possible bias of this approach is this assumed absence of variation in lengths of the gestation and of dry period. Although variation in gestation lengths are low for cattle (Norman et al., 2009), variations of the length of the dry period can be large (Drackley, 1999). Lactation lengths and lengths of the calving intervals are important parameters for estimation of MPL in all approaches. Hence, records of the last calving date and the predicted next calving date are essential. Cows that are not pregnant yet should be excluded from the datasets because no estimate of the calving interval can be made. Alternatively, it may be assumed that the average length of the calving interval of the other cows at the same farm resembles the calving interval for the cows for which no estimate can be made. In the present study, we estimated MPL for herds based on lactating cows only. The method can include dry cows also by assessing total herd production and dividing this by the number of adult cows (cows having calved at least once including the dry cows) and MPL is calculated by multiplying the average $\mathrm{MP}_{t}$ per cow by the number of days in the calving interval.

In smallholder system in developing countries, where these alternative methods are targeted, data for assessment of farm performance are incomplete and imperfect (Desiere et al., 2016; Fraval et al., 2018; Pica-Ciamarra et al., 2014; Rege et al., 2011; Zezza et al., 2016). Lack of information about the feeding regime is part of the imperfectness and incompleteness as is the lack of knowledge about parity. Including feeding data next to milk production records to predict MPL would hamper, therefore, the adoption and application of the alternative methods.

\section{Conclusion}

We assessed the accuracy of MPL-estimates from alternative data recording methods with a limited number of TD or recall records or a single TD or recall record per lactation. For MPL-estimates derived at cow level, the accuracy was highest for LTD (RMAE, 15\%), and lowest for SRM (RMAE, 28\%), while accuracies for STD and LRM were intermediate. For MPL-estimates derived at herd level, the accuracy was higher for STD (RMAE, 13\%) than for SRM (RMAE, 20\%). Methods 
based on a limited number of TD and on farmers' recall data required larger effective sample sizes to detect significant effects when compared to the benchmarks. Dependent on the objective of studies, however, alternative data recording methods provide labor-saving and cost-effective ways to estimate MPL in data-scarce smallholder dairy systems.

\section{CRediT authorship contribution statement}

S.A. Migose: Conceptualization, Data curation, Formal analysis, Writing - original draft. A. van der Linden: Conceptualization, Methodology, Formal analysis, Writing - review \& editing. B.O. Bebe: Funding acquisition, Writing - review \& editing. I.J.M. de Boer: Supervision, Writing - review \& editing. S.J. Oosting: Funding acquisition, Supervision, Writing - review \& editing.

\section{Acknowledgements}

This study was supported by the NUFFIC (Netherlands Organization for International Cooperation in Higher Education) under the project NICHE-KEN-127: Build capacity to deliver competent graduates for enhanced competitiveness in the dairy value chain. Requested by Egerton University and provided by Wageningen University. We are grateful to the manager of Dairy Recording Services of Kenya and the officers of the Livestock Recording Centre for providing TD data, and the livestock extension officers for guiding the process of collection of recall data. We acknowledge the farmers and stakeholders in the Kenyan dairy sector for their participation in the survey. We are grateful to Simon Fraval and Akke Kok for their valuable inputs in calculating effective sample sizes.

\section{Conflict of Interest}

None.

\section{Appendix A}

The formulas described in Cohen (1988) were used to calculate the effective sample sizes (Eqs (A1)-(A3)).

$$
\begin{aligned}
& \delta=\left(t_{1-\alpha}-t_{1-\beta}\right) \\
& d=\frac{m_{A}-m_{B}}{\sigma} \\
& d=d^{*} \sqrt{r_{y y}}
\end{aligned}
$$

where $\delta$ is the critical values of $\mathrm{t}$ at $t_{1-\alpha}$ and $t_{1-\beta}, \alpha$ is the probability of a type I error, ${ }_{\beta}$ the probability of a the type II error, $d$ is the standardized effect size, $m_{A}$ and $m_{B}$ are the means of populations A and B, respectively (e.g. before and after an intervention), $\sigma$ is the population standard deviation, $r_{y y}$ is the reliability coefficient $\left(R^{2}\right)$. The two populations were assumed to have equal variances and an equal reliability coefficient, $\alpha$ was set at $P=0.05$ (one-tailed), and $\beta$ at $P=0.20$.

\section{References}

Adediran, S.A., Malau-Aduli, A.E.O., Roche, J.R., Donaghy, D.J., 2007. Editor) Current Topics in Dairy Production.

Beegle, K., Carletto, C., Himelein, K., 2012. Reliability of recall in agricultural data. J. Dev. Econ. 98, 34-41.

Bellocchi, G., Rivington, M., Donatelli, M., Matthews, K., 2011. Validation of biophysical models: issues and methodologies. Sustainable Agriculture Volume 2. Springer, pp. 577-603.

Bennett, N.D., Croke, B.F.W., Guariso, G., Guillaume, J.H.A., Hamilton, S.H., Jakeman, A.J., Marsili-Libelli, S., Newham, L.T.H., Norton, J.P., Perrin, C., 2013. Characterising performance of environmental models. Environ. Model. Softw. 40, 1-20.

Berry, D.P., Olori, V.E., Cromie, A.R., Veerkamp, R.F., Rath, M., Dillon, P., 2005. Accuracy of predicting milk yield from alternative milk recording schemes. Anim. Sci. 80, 53-60.

Bibby, J., Toutenburg, H., 1977. Prediction and Improved Estimation in Linear Models John Wiley \& Sons, Chichester, UK.

Cohen, J., 1988. Statistical power analysis for the behavioral sciences 2nd edn.

De Mel, S., McKenzie, D.J., Woodruff, C., 2009. Measuring microenterprise profits: must we ask how the sausage is made? J. Dev. Econ. 88, 19-31.

de Nicola, F., Giné, X., 2014. How accurate are recall data? Evidence from coastal India. J. Dev. Econ. 106, 52-65. https://doi.org/10.1016/j.jdeveco.2013.08.008.

Deininger, K., Carletto, C., Savastano, S., Muwonge, J., 2012. Can diaries help in improving agricultural production statistics? Evidence from Uganda. J. Dev. Econ. 98, $42-50$.

Desiere, S., Staelens, L., D'Haese, M., 2016. When the data source writes the conclusion: evaluating agricultural policies. J. Dev. Stud. 52, 1372-1387. https://doi.org/10 $1080 / 00220388.2016 .1146703$.

Drackley, J.K., 1999. Biology of dairy cows during the transition period: the final frontier? J. Dairy Sci. 82, 2259-2273.

Duclos, D., Gokhale, S., Bacilieri, R., Ducrocq, V., 2008. Simplified milk-recording protocols adapted to low-input environments with very small herd size. Animal 2 160-166. https://doi.org/10.1017/S1751731107000985.

Flores, E.B., Kinghorn, B.P., van der Werf, J., 2013. Predicting lactation yields in dairy buffaloes by interpolation and multiple trait prediction. Livest. Sci. 151, 97-107. https://doi.org/10.1016/j.livsci.2012.10.017.

Fraval, S., Hammond, J., Wichern, J., Oosting, S.J., De Boer, I.J.M., Teufel, N., Lannerstad, M., Waha, K., Pagella, T., Rosenstock, T.S., Giller, K.E., Herrero, M., Harris, D., Van Wijk, M.T., 2018. Making the most of imperfect data: a critical evaluation of standard information collected in farm household surveys. Exp. Agric. 55,
1-21. https://doi.org/10.1017/s0014479718000388.

Godlonton, S., Hernandez, M.A., Murphy, M., 2018. Anchoring bias in recall data: evidence from Central America. Am. J. Agric. Econ. 100, 479-501. https://doi.org/10. 1093/ajae/aax080.

ICAR, 2017. Section 2 - Guidelines for Dairy Cattle Milk Recording. Guidelines.

ILRI, 2015. Management of Dry Cows. ILRI Publ.

Jenkins, T.G., Ferrell, C.L., 1984. A note on lactation curves of crossbred cows. Anim. Sci. 39, 479-482.

Kanyongo, G.Y., Brook, G.P., Kyei-Blankson, L., Gocmen, G., 2007. Reliability and statistical power: how measurement fallibility affects power and required sample sizes for several parametric and nonparametric statistics. J. Mod. Appl. Stat. Methods 6, 9.

Katiku, P.N., Gachuiri, C.K., Mbugua, P.N., 2011. Characterization of dairy cattle farming in Mbeere District of Eastern Kenya [WWW document]. Livest. Res. Rural Dev URL. http://www.lrrd.org/lrrd23/11/kati23236.htm.

Kong, L., Li, J., Li, R., Zhao, X., Ma, Y., Sun, S., Huang, J., Ju, Z., Hou, M., Zhong, J., 2018 Estimation of 305-day milk yield from test-day records of Chinese Holstein cattle. J. Appl. Anim. Res. 46, 791-797.

Kosgey, I.S., Mbuku, S.M., Okeyo, A.M., Amimo, J., Philipsson, J., Ojango, J.M., 2011 Institutional and organizational frameworks for dairy and beef cattle recording in Kenya: a review and opportunities for improvement. Anim. Genet. Resour. génétiques Anim. genéticos Anim. 48, 1-11.

Landete-Castillejos, T., Gallego, L., 2000. The ability of mathematical models to describe the shape of lactation curves. J. Anim. Sci. 78, 3010-3013.

Liu, Z., Reents, R., Reinhardt, F., Kuwan, K., 2000. Approaches to estimating daily yield from single milk testing schemes and use of am-pm records in test-day model genetic evaluation in dairy cattle. J. Dairy Sci. 83, 2672-2682.

Macciotta, N.P.P., Dimauro, C., Rassu, S.P.G., Steri, R., Pulina, G., 2011. The mathematical description of lactation curves in dairy cattle. Italian J. Animal Sci. 10 (4), 213-223. https://doi.org/10.4081/ijas.2011.e51.

Macciotta, N.P.P., Vicario, D., Pulina, G., Cappio-Borlino, A., 2002. Test day and lactation yield predictions in Italian simmental cows by ARMA methods. J. Dairy Sci. 85, 3107-3114. https://doi.org/10.3168/jds.S0022-0302(02)74398-1.

Mason, N.W.H., Holdaway, R.J., Richardson, S.J., 2018. Incorporating measurement error in testing for changes in biodiversity. Methods Ecol. Evol. 9, 1296-1307.

McGill, D.M., Thomson, P.C., Mulder, H.A., Lievaart, J.J., 2014. Strategic test-day recording regimes to estimate lactation yield in tropical dairy animals. Genet. Sel. Evol. $46,78$.

Migose, S.A., Bebe, B.O., de Boer, I.J.M., Oosting, S.J., 2018. Influence of distance to urban markets on smallholder dairy farming systems in Kenya. Trop. Anim. Health Prod. 50, 1417-1426. https://doi.org/10.1007/s11250-018-1575-x.

Muasya, T.K., Peters, K.J., Kahi, A.K., 2014. Effect of diverse sire origins and 
environmental sensitivity in Holstein-Friesian cattle for milk yield and fertility traits between selection and production environments in Kenya. Livest. Sci. 162, 23-30. https://doi.org/10.1016/j.livsci.2014.01.017.

Muraguri, G.R., McLeod, A., Taylor, N., 2004. Estimation of milk production from smallholder dairy cattle in the coastal lowlands of Kenya. Trop. Anim. Health Prod. 36, 673-684. https://doi.org/10.1023/b:Trop.0000042850.73205.93.

Mwendia, S.W., Mwungu, C.M., Ng'ang'a, S.K., Njenga, D., Notenbaert, A., 2018. Effect of feeding oat and vetch forages on milk production and quality in smallholder dairy farms in Central Kenya. Trop. Anim. Health Prod. 50, 1051-1057. https://doi.org/10, 1007/s11250-018-1529-3.

Njubi, D., Rege, J.E.O., Thorpe, W., Collins-Lusweti, E., Nyambaka, R., 1992. Genetic and environmental variation in reproductive and lactational performance of Jersey cattle in the coastal lowland semi-humid tropics. Trop. Anim. Health Prod. 24, 231-241. https://doi.org/10.1007/bf02356752.

Njubi, D.M., Wakhungu, J., Badamana, M.S., 2009. Milk yield prediction in Kenyan Holstein-Friesian cattle using computer neural networks system. Livest. Res. Rural Dev. 21. https://doi.org/10.1590/S0102-09352008000400035.

Norman, H.D., Wright, J.R., Kuhn, M.T., Hubbard, S.M., Cole, J.B., Van Raden, P.M., 2009. Genetic and environmental factors that affect gestation length in dairy cattle. J. Dairy Sci. 92, 2259-2269.

Ojango, J.M.K., Mrode, R., Rege, J.E.O., Mujibi, D., Strucken, E.M., Gibson, J., Mwai, O., 2019. Genetic evaluation of test-day milk yields from smallholder dairy production systems in Kenya using genomic relationships. J. Dairy Sci. https://doi.org/10.3168/ jds.2018-15807.

Omore, A.O., McDermott, J.J., Arimi, S.M., Kyule, M.N., Ouma, D., 1996. A longitudinal study of milk somatic cell counts and bacterial culture from cows on smallholder dairy farms in Kiambu District, Kenya. Prev. Vet. Med. 29, 77-89. https://doi.org/10. 1016/S0167-5877(96)01054-9.

Otwinowska-Mindur, A., Ptak, E., Jagusiak, W., Satoła, A., 2014. Modeling lactation curves of Polish Holstein-Friesian cows. Part II: prediction of 305-d lactation milk, fat and protein yields. J. Anim. Feed Sci. 675, 127.

Phillips, G.W., Jiang, T., 2016. Measurement error and equating error in power analysis. Pract. Assess. Res. Eval. 21.

Pica-Ciamarra, U., Baker, D., Morgan, N., Zezza, A., Azzarri, C., Ly, C., Nsiima, L., Nouala, S., Okello, P., Sserugga, J., 2014. Investing in the livestock sector: why good numbers matter. A Sourcebook for Decision Makers on How to Improve Livestock Data. World Bank. https://doi.org/10.1596/17830.

Quist, M.A., LeBlanc, S.J., Hand, K.J., Lazenby, D., Miglior, F., Kelton, D.F., 2007. Agreement of predicted 305-day milk yields relative to actual 305-day milk weight yields. J. Dairy Sci. 90, 4684-4692. https://doi.org/10.3168/jds.2006-833.

R Core Team, 2018. R: a language and environment for statistical computing. https://doi. org/10.1007/978-3-540-74686-7.

Rege, J.E.O., Marshall, K., Notenbaert, A., Ojango, J.M.K., Okeyo, A.M., 2011. Pro-poor animal improvement and breeding - what can science do? Livest. Sci. 136, 15-28. https://doi.org/10.1016/j.livsci.2010.09.003.

Richards, S., VanLeeuwen, J.A., Shepelo, G., Gitau, G.K., Wichtel, J., Kamunde, C., Uehlinger, F., 2016. Randomized controlled trial on impacts of dairy meal feeding interventions on early lactation milk production in smallholder dairy farms of Central Kenya. Prev. Vet. Med. 125, 46-53.

Sawyer, G.J., Speijers, E.J., Morris, R.J., Coupar, F.J., 1994. Characterising lactation curves in heifers of different breeds first calved in moderate or low condition. In: Proceedings-Australian Society of Animal Production. Australian society of animal production, pp. 128.

Staal, S.J., Omore, A.O., 1998. Use of farmer recall versus direct measurement in gathering lactation data: lessons from Kenyan smallholder dairy systems. Br. Soc. Anim. Sci.

Theil, H., Rey, G., 1966. A quadratic programming approach to the estimation of transition probabilities. Manage. Sci. 12, 714-721.

Trivedi, K.R., 1997. Dairy recording in Kenya. In: Trivedi, K.R. (Ed.), International Workshop on Animal Recording For Smallholders in Developing Countries, 20-23 October 1997. ICAR Tech. Ser., pp. 1.

Van Raden, P.M., 1997. Lactation yields and accuracies computed from test day yields and (co) variances by best prediction. J. Dairy Sci. 80, 3015-3022.

Wasike, C.B., Kahi, A.K., Peters, K.J., 2011. Modelling of lactation curves of dairy cows based on monthly test day milk yield records under inconsistent milk recording scenarios. Animal 5, 1780-1790. https://doi.org/10.1017/S1751731111000954.

Zezza, A., Federighi, G., Kalilou, A.A., Hiernaux, P., 2016. Milking the data: measuring milk off-take in extensive livestock systems. Experimental evidence from Niger. Food Policy 59, 174-186. https://doi.org/10.1016/j.foodpol.2016.01.005. 